\title{
Catorce principios pedagógicos que dimanan del Paradigma Tri Dimensional (PTD) del Nuevo Humanismo
} Fourteen Pedagogical Principles Arising From the ThreeDimensional Paradigm (TDP) of the New Humanism

\author{
Miguel Baraona ${ }^{1}$ \\ Universidad Nacional \\ Willy Castro Guzmán ${ }^{2}$ \\ Universidad Nacional \\ David Muñoz ${ }^{3}$ \\ Colegio Humanístico Costarricense
}

Costa Rica

\begin{abstract}
Resumen
Este artículo trata de catorce proposiciones pedagógicas generales que, a nuestro juicio, se desprenden del Paradigma Tri Dimensional (PTD) que hemos venido trabajando un grupo de académicos del Centro de Estudios Generales (CEG) de la Universidad Nacional (UNA) de Costa Rica. Estos principios están
\end{abstract}

1. Escritor y antropólogo. Estudió Sociología en Francia en la Escuela de Altos Estudios en Ciencias Sociales. Posee un Doctorado en Antropología por la Universidad de Texas en Austin. Académico de la Universidad Nacional, donde coordina la Cátedra de Humanismo para el Tercer Milenio. Vicedecano del CEG desde el año 2015. Correo electrónico: miguel.baraona.cockerell@una.cr

2. Posee un Doctorado en Informática y Comunicación Centrada en el Ser Humano, por la Universidad de Aalborg. Máster en Tecnologías de Información y Comunicación con énfasis en Administración de Proyectos de TI. Bachiller en Informática por la Universidad Nacional. Coordinador del Programa UNA Virtual de la UNA del 2007 al 2014. Docente Universitario. Correo electrónico: willy.castro.guzman@una.cr

3. Egresado de la Licenciatura en Psicología, Universidad Nacional de Costa Rica. Egresado de la Maestría en Humanismo, Sociedad y Ambiente, Universidad Nacional de Costa Rica. Coordinador general de la Comisión de Cultura, Deportes y Recreación de la FEUNA. Actualmente es integrante de la Cátedra Ibn Jaldún en la Universidad Nacional y docente del Colegio Humanístico Costarricense. Correo electrónico:davomu@gmail.com 
solo esbozados de manera preliminar en este artículo y requieren de un mayor análisis y profundización en los años venideros. Están basados en lo que llamamos el PTD, que fuera desarrollado en el contexto de la Cátedra Rolando García de humanismo, complejidad e interdisciplina, y que ha sido presentado en numerosos artículos y en un libro publicado en 2017, titulado Hacia una epistemología del Nuevo Humanismo. Por parte, esta propuesta pedagógica se basa también en una visión crítica de la evolución de las principales escuelas de pensamiento e investigación al respecto, aunque se reconoce en consonancia con algunas de ellas, en especial con el constructivismo piagetiano, y las proposiciones del gran pedagogo Paulo Freire. Los principios aquí presentados están concebidos en tanto mediaciones pedagógicas entre el PTD ya mencionado y el trabajo áulico regular, y en tanto docentes universitarios y las personas estudiantes. Todos esos 14 principios pedagógicos apuntan a estimular desde el punto de vista metodológico-práctico la participación protagónica creciente de los educandos en el proceso de enseñanza-aprendizaje. A su vez, todos ellos confluyen hacia un mismo objetivo esencial, que es el desarrollo autónomo de los estudiantes para expandir su capacidad de pensar críticamente su propia realidad interna y el mundo circundante. Esta capacidad para ejercer el pensamiento crítico nace del desarrollo conjugado de siete atributos indispensables (estrechamente asociados a los 14 principios pedagógicos de marras) que discutimos en las conclusiones de este artículo: integridad, objetividad, empatía, racionalidad, autonomía, justicia e introspección.

Palabras clave: Nuevo Humanismo; paradigma tri-dimensional; principios pedagógicos; protagonismo estudiantil; pensamiento crítico.

\begin{abstract}
This article is about fourteen general pedagogical propositions that, in our opinion, arose from the Three-Dimensional Paradigm (TDP) that a group of scholars from the Center for General Studies (CEG) of the National University (UNA) of Costa Rica has been working on. These principles are merely preliminarily outlined in this article and require further analysis and deepening in the coming years. They are based upon what we have termed as the TDP, conceived within the context of the Rolando García Chair of Humanism, Complexity, and Interdiscipline, and addressed in numerous articles and a book published in 2017 titled Towards an Epistemology of New Humanism. On the other hand, this pedagogical proposal is also founded upon a critical vision of the evolution of the main schools of thought and research on this subject, although it recognizes to agree with some of them, especially with Piagetian constructivism and the great educator Paulo Freire's proposals. University teachers and students, themselves, conceived the principles addressed here; they were developed as pedagogical mediations between the TDP already mentioned and the regular classroom work. All these fourteen pedagogical principles aim at stimulating, from a methodological and practical point of view, the increasing participation of students
\end{abstract}


in the teaching-learning process. In turn, all of them flow towards the same essential goal, which is the autonomous development of students to expand their capacity to think critically about their internal reality and the surrounding world. This capacity to exercise critical thinking arises from the combined development of seven essential attributes (closely associated with the fourteen pedagogical principles) discussed in the conclusions of this article: integrity, objectivity, empathy, rationality, autonomy, justice, and introspection.

Keywords: New Humanism; three-dimensional paradigm; pedagogical principles; student protagonism; critical thinking.

El pensamiento lleva al conocimiento. Una persona puede ver y escuchar, leer y aprender cuanto desee; pero nunca será verdadero conocimiento sino aquello que ha pensado con detenimiento y que mediante ese proceso se ha vuelto una

propiedad de su mente.

¿Es entonces afirmar demasiado cuando digo que el ser humano solo pensando se vuelve realmente humano?

Quitad el pensamiento de la vida del ser humano, ¿y qué es lo que queda?

Johann Heinrich Pestalozzi

\section{Introducción}

¿Qué dudas pueden caber acerca de la tarea de la docencia como una de las más nobles, indispensables, y difíciles de ejercer, de todos los oficios que existen desde que surgieron como labores imperativas de las sociedades complejas hace miles de años atrás? Esto, reconociendo que no sabemos con exactitud cómo se llevaba a cabo de manera más o menos formal e institucionalizada en muchas civilizaciones que han aparecido y desaparecido a lo largo de los últimos 10 mil años, desde que, según todo lo que sabemos al respecto, las mujeres inventaran la agricultura en la alta Mesopotamia donde hoy se encuentra Turquía. ${ }^{4}$ Pero la educación no solo ha existido en las sociedades complejas. Todos los pueblos, todas las culturas y todos los millares de formas de organización de la vida social que han existido y existen aún hoy, desde que nuestra especie apareciera por evolución natural en las estepas africanas hace circa 280000 años atrás hasta nuestros días, han tenido mecanismos y tradiciones orientadas a la transmisión de saberes acumulados de una generación a otra. Se trata, por tanto, de una instancia decisiva en la sobrevivencia de nuestra especie y en la evolución sociocultural de la humanidad, desde sus orígenes hasta el presente. Pero, ¿cuáles han sido las

4 Una invención crucial para el desarrollo de las sociedades complejas, y que ya Federico Engels (1884) había señalado en su obra clásica, y que muchos trabajos posteriores han corroborado. Ver: Adovasio, Soffer y Page (2007). 
modalidades más efectivas de transmisión de conocimientos entre generaciones? ¿Cuáles son los rasgos universales básicos de dicho proceso? ¿Cuáles también sus modalidades a través del tiempo y las culturas? Imposible saberlo por ahora, pero imaginamos que, en esencia, hay dos principios inescapables que debemos considerar como un mínimo común denominador: 1. Que esa transferencia de saberes de los sujetos mayores a los más jóvenes de un determinado grupo social debe ser, de alguna forma, un proceso efectivo y de impacto duradero y positivo. 2. Que debe ser una experiencia plenamente aceptada y gratificante para los recipientes; que debe dejar espacio para que se formulen nuevas ideas, y que nuevos conocimientos puedan ser incorporados al patrimonio cultural vivo de la colectividad.

Como ya nos enseñaron a comprenderlo quienes se dedican a la ciencia de la ecología, una de las primeras disciplinas más o menos nuevas completamente basadas en la aplicación de la teoría de sistemas y en métodos derivados de esta perspectiva epistemológica, toda organización o estructura intrincada requiere de flujos constantes de materiales, energía e información para sostenerse en el tiempo, y adaptarse a entornos cambiantes y, a menudo, desafiantes. En otras palabras y en lo tocante a nuestra especie y sus sistemas sociales complejos: transferencia exitosa de conocimientos y estímulo a la creatividad y al descubrimiento (Spirkin, 1983). En muchas épocas de la evolución sociocultural de la humanidad estos dos requisitos, de seguro, eran cuestión de vida o muerte, cuando se vivía al límite de la sobrevivencia. Saber manejar la vida individual y colectiva dentro de ciertos parámetros inescapables, para no incurrir en conductas autodestructivas conducentes a la extinción grupal, es de importancia decisiva.

Ahora bien, en nuestra época, ¿qué se puede esperar y desear de una educación apropiada para confrontar tanto los problemas societales que nos aquejan como para mirar hacia un porvenir que no esté amenazado por la espada de Damocles con un desastre de proporciones apocalípticas? Esa es la interrogante central que, de forma muy sucinta, se intenta responder desde el ángulo de una pedagogía nuevo humanista, en este trabajo.

Las nociones de nuevo humanismo propuestas en varios trabajos publicados a la fecha (Baraona, 2011, 2014, 2015, 2017a, 2017b) no pretenden ser una doctrina monolítica labrada en piedra, sino que constituyen, apenas, una propuesta germinal no excluyente de muchas otras que podrían ser también formuladas. En los años venideros esperamos avanzar en dirección a una formulación más acabada de lo que entendemos por nuevo humanismo. 
El trabajo colectivo e individual que se ha desplegado en el Centro de Estudios Generales de la Universidad Nacional de Costa Rica en los últimos años, en torno al nuevo humanismo, se ha concentrado especialmente en establecer lineamientos prácticos, con una buena fundamentación teórica y metodológica, para el desarrollo de nuestra labor académica en el terreno de la docencia y de la investigación. Uno de esos esfuerzos ha estado constituido por la Cátedra Rolando García de humanismo, complejidad e interdisciplina (2016-2017), de donde salieron un artículo y un libro colectivo, y dos algoritmos para la elaboración de cursos e investigaciones interdisciplinarias.

De modo que el presente trabajo intenta alcanzar dos metas esenciales: 1. Establecer las bases de una pedagogía apropiada para el trabajo interdisciplinario en docencia. 2. Darle al PTD del nuevo humanismo un asidero pedagógico más concreto y mejor definido.

\section{El paradigma tridimensional (PTD) del nuevo humanismo}

El humanismo se puede definir desde dos ángulos, el primero está asociado a la capacidad innata del ser humano para formular lenguaje complejo que, gracias al proceso de hominización y evolución del neo-cortex, se basa en una compleja red neuronal que permite el surgimiento de las habilidades lingüísticas y de representación simbólica, de donde deviene el proceso más importante para nuestros fines analíticos: La capacidad de autorreferencia ${ }^{5}$ y el potencial narrativo. Nuestra naturaleza ha estado condicionada por nuestros procesos imaginativos, la cognición y las narrativas colectivas sobre nuestro propio origen y ontogénesis que representaría la posibilidad de universos simbólicos, cosmovisiones, espiritualidad, pensamiento mágico-religioso y, en resumidas cuentas, la cultura como producto de la construcción colectiva de la realidad. A este aspecto esencial del ser humano lo reconocemos como el sentido lato del humanismo: La capacidad innata del ser humano para elaborar narrativas que guían la búsqueda incesante e inacabada de su esencia, siempre desde una determinada perspectiva cultural. La redefinición de aquello que se considera "lo humano", o al menos aquello que es deseable en tanto expresión superior de su naturaleza.

5 Refiere a la capacidad del ser humano para poder pensarse y representarse a sí mismo, lo cual deviene de la capacidad de inferir los mismos procesos cognitivos en los otros elementos de la especie.

6 Es producto de la consciencia auto-referencial colectiva de donde parten las explicaciones sobre el origen y el destino común de la especie representadas por alguna perspectiva cultural, una cosmovisión y el universo simbólico que es base de la cultura, la etnicidad y la religiosidad. 
La segunda dimensión comprende los discursos explícitos cuya centralidad es lo estrictamente humano. Son narrativas cada vez más alejadas de la divinidad que se consolidaron en la condición humana como corpus teórico-filosófico, en los cuales se agrupan reflexiones explícitas y abordajes de problemas ontológicos. Estas definiciones se desarrollaron como brotes históricos, a saber: Greco-Romano, Edad de Oro islámica, renacentista y el liberal, conformando el sentido estricto del humanismo, la doctrina o postura ético-filosófica sobre el lugar del ser humano en el universo y, sobre todo, su rumbo.

La base de estas doctrinas es la capacidad del ser humano para autoemanciparse de los procesos que oprimen su condición y la capacidad para forjar su destino. Anudado con el sentido lato, los orígenes de estas formulaciones están en la capacidad de autorreferenciarse arraigada a nuestra constitución cerebral $y$ es el argumento de la existencia concreta de una esencia humana compartida que nos hace tendientes a la autoemancipación.

Frente a nuestra definición, surgen cuestionamientos recurrentes sobre la propuesta de un nuevo humanismo, tal como si: ¿Es esta propuesta el reconocimiento de un nuevo periodo o brote humanista? ¿Pretende recuperar los valores de algún brote histórico en especial para su aplicación en el contexto del siglo XXI? Las respuestas son negativas, pues esta propuesta, si bien se basa en la tesis de la tendencia de los grupos humanos a la emancipación propia, representa, sobre todo, una forma distinta de producir y fundamentar el conocimiento humano para los fines de una nueva ética de la vida social, por medio de la investigación de los fenómenos complejos e hipercomplejos: una epistemología.

De los humanismos precedentes, se recogen cinco principios que distinguen cualquier doctrina de un genuino postulado humanista: Naturalismo, que señala el comienzo de una búsqueda más racional sobre las causas y consecuencias de los fenómenos de la naturaleza (incluyendo al ser humano). Protagonismo, como la concepción prometeica en la que nuestra especie es concebida como forjadora de su propio destino, al rechazar la idea de ser determinados por fuerzas sobrenaturales. Perfectibilidad, es el perfeccionamiento posible del ser humano en su entorno: vida social e individual. Individualismo, en tanto todo ser humano merece de manera individual los mismos derechos inherentes a su condición y, en íntima relación, el Esencialismo, que propone que los seres humanos más allá de la clase, etnia, género, religión o nación poseen una esencia común e inalienable (Baraona y Mora). A estos principios, el PTD-NH agrega otros tres que no solo incorporan y resignifican en un conjunto sistémico conceptual los otros anteriores, sino que aportan una forma distinta de asociar el papel del conocimiento 
científico, la relación del ser humano con el ambiente y la necesidad de transformación del marco económico-social, de lo cual resultan tres dimensiones:

\section{Dimensión sociocultural: de la competencia a la solidaridad}

La industrialización, la división social del trabajo y la migración del campo a los centros metropolitanos formaron parte de la configuración económica, cultural y política del sistema mundo en los albores del capitalismo industrial. La promesa de la ilustración, basada en las libertades individuales, la secularidad y los derechos inalienables, fueron bases de su contenido originalmente emancipatorio para formar parte de la estructura cultural e ideológica de dominación de las masas en beneficio de la clase dominante emergente, de la justificación de conflictos entre potencias centrales y periféricas, de la expansión económica imperialista y de la modernización del modelo productivo. Lo valores del liberalismo tornaron en una suerte de darwinismo social ${ }^{7}$, donde la competencia medía las posibilidades de realización y sobrevivencia de amplios y distintos sectores de la sociedad global que conformaron una clase subalterna, mientras se producía la concentración de riquezas más grande de la historia de la humanidad en el siglo XIX, en manos de reducidos grupos de poder que fueron consolidándose en el siglo XX. La globalización, como un macroproceso de expansión de capitales, no solo modificó los marcos geopolíticos, sino que propició una corriente homogenizadora de valores y narrativas que, apegada al evolucionismo social (Gonzáles, 1984) y al individualismo egoísta (Baraona y Mora, 2017) orientaron la praxis social hegemónica.

Lejos de entender el humanismo liberal como el motor ideológico del capitalismo moderno, se reconocen en la tergiversación de sus principios esenciales, la naturalización de los procesos de expansión del capitalismo global: la formación de un ciudadano libre de consumir según su capacidad y su escogencia, protegido por una democracia del consumo en el mercado, enajenado, con un visible deterioro de su vida colectiva e interior (reflexibilidad y criticidad) y una serie de características que aproximan a entender la vivencia del ser humano en la hipermodernidad como un anti-humanismo propiciado por la competencia como dogma, el consumo como espejismo de "participación popular" y la competencia como el individualismo funcional, engranaje esencial de la meta-cultura del

7 Es la ideología política que concibe la sociedad como un gran organismo que responde a las leyes evolutivas de la biología, donde el nivel de adaptabilidad a las condiciones ambientales es lo que determina la sobrevivencia de una configuración genética sobre otra menos oportuna para los fines de preservar la especie. El darwinismo social, según Gonzalez Vicén (1984), es una ideología, más no una filosofía o una sociología de la organización social, puesto que funge únicamente como un justificante seudocientífico de la estructura social de división de clases. 
capital. ${ }^{8}$ El nuevo humanismo no es una postura meramente ético-filosófica, sino que es base intelectual para la praxis humanista. En este sentido, el paso de la competencia a la solidaridad se materializa en la conformación de procesos colectivos guiados por el altruismo, acciones concentradas y decisiones consensuadas: Los movimientos sociales.

\section{Dimensión ético-filosófica: del antropocentrismo al antropoholismo}

La concepción del ser humano frente al universo (entiéndase naturaleza) ha sido un eje cardinal de la formulación ético-filosófica. El antropocentrismo se proponía como una doctrina que postulaba, con desdén, la superioridad de la racionalidad humana por encima de los procesos políticos, religiosos y bélicos. Esta concepción antropocéntrica nace, entonces, revestida del mito prometéico ${ }^{9}$ que en la Ilustración se interpreta como privilegio a la dimensión cognitiva del ser humano, siempre en búsqueda intelectual, autonomía del pensamiento científico $\mathrm{y}$, por ende, de buscar las explicaciones de los fenómenos en el mundo natural (naturalismo). Desde la emergencia del sistema económico capitalista y las configuraciones socioculturales que supone, esta centralidad en lo humano fue constituyéndose en un antropocentrismo radical con graves carencias éticas cada vez más agudas. El antropocentrismo radical, sumado al individualismo egoísta, resultaron no solo en esta superación, sino que avanzó hacia una visión mesiánica de dominación de la naturaleza y sometimiento de las culturas precapitalistas. El resultado, en el siglo XXI, es una naturaleza reducida a recursos para la producción industrial a escala global (materia prima) y una situación ambiental que en su deterioro continuo anuncia la inminente desaparición de las condiciones naturales necesarias para la subsistencia de la vida humana.

Frente a los embates de este proceso, la ecología como una disciplina de enfoque híbrido conformada por las llamadas "ciencias de la tierra" comienza la primera parte de su desarrollo sin incluir al ser humano y su actividad dentro del estudio de la vida natural, hasta que, en 1921, la inclusión parcial del papel humano conformaría una ecología reduccionista donde aún los procesos sociales no serían

8 Este término explica un proceso que trasciende las esferas culturales específicas y las reúne bajo los principios homogenizadores que regulan su marco existencial.

9 La tragedia del poeta griego Esquilo (siglo IV a. C.), "Prometeo encadenado", narra el castigo al titán Prometeo, otorgado por Zeus, padre de los dioses del Olimpo, en mérito de haberle robado la fuente de donde emana el fuego a Efeso, para entregársela a la humanidad en símbolo de desafío a la tiranía de los dioses. Un mito que representa uno de los primeros testimonios de la noción de autoemancipación como tendencia esencial y justificada del ser humano. 
tomados en cuenta. Posteriormente, Murray Bookchin (1995) cimenta las bases de la ecología social, la cual comienza a reconocer al ser humano en tanto un ente biológico de una importancia equiparable a la del resto de especies. En contraste con este papel periférico de los procesos humanos en la ciencia natural, algunas posturas ecologistas, que podríamos reconocer como radicales, han planteado en el marco de los movimientos sociales una corriente ética que considera oportunas, para la conservación del ambiente, otras formas de vida al mismo nivel de los grupos humanos e, incluso, postular la necesidad de su desaparición como especie. $^{10}$

El reduccionismo positivista es el principal objeto de crítica en el nuevo humanismo, puesto que no contempla la influencia de los procesos sociales, los sistemas de poder y la dominación como directamente relacionados al extractivismo ecológico capitalista. El antropoholismo entiende al ser humano como un ente biológico de un rol preponderante para la conservación del planeta, pues en la relación cultura-natura es donde las contradicciones sociales se proyectan en la relación con el sistema ecológico.

\section{Dimensión cognoscitiva: del mecanicismo a los modelos de análisis complejos}

Toda narrativa explícita sobre las consignas emancipadoras que debe asumir la humanidad han dado paso a nuevas perspectivas cognoscitivas, lo cual ha supuesto la conformación de centralidades epistemológicas que responden a las necesidades de la ciencia, de la orientación cognitiva y de los procesos sociales, lo que García (2006) denomina: un marco epistémico, un conjunto de ideas provenientes del sistema de conocimiento científico que toman sentido predominante solo con respecto a determinado momento histórico social; es decir, la conjunción de lo científico, lo psicocognitivo y lo sociocultural, diferenciándose así este concepto del "paradigma" de Thomas Kuhn (1971) que, según Jean Piaget (1982), explica el progreso científico desde la sociología de la ciencia, sin tomar en cuenta los elementos y mecanismos racionales que operan en esta evolución en tanto una teoría ex post facto.

10 Podría mencionarse al movimiento por la extinción humana voluntaria (VHEMT, por sus siglas en inglés) como uno de la primera organización que desde el 2008 agrupa a personas, principalmente de Estados Unidos, que apuestan por el control estricto de la natalidad para la disminución procesual de los elementos que conforman la especie humana en aras de que el planeta recupere sus características esenciales. Esta propuesta puede revisarse de manera detallada en ensayos como el de Knight (2015). 
En el siglo XXI, la necesidad de un modelo integrado de análisis de los fenómenos sociales y naturales deviene de la crisis del positivismo que, en el siglo pasado, demostró que el mecanicismo científico puede seguir dando respuestas delimitadas y efectivas de fenómenos de estabilidades, que pueden parecer aislados, pero que, al momento de avanzar hacia las interacciones con los procesos sociales, pierde toda posibilidad de predictibilidad, cuantificación y determinación. Desde el estructuralismo sistémico de Jean Piaget (1974), la corriente de la complejidad de Edgar Morín y los aportes sustanciales de orden teórico-metodológico de los sistemas complejos de Rolando García, la epistemología de la complejidad ha ofrecido una ruta para la construcción de metodologías meta-disciplinarias. La complejidad y sus procesos de aprehensión del mundo pueden definirse como una propiedad inherente a la realidad objetiva ajena a nuestra comprensión, que solo mediante la conceptualización de sus elementos en forma de subsistemas de interacción y flujo, como propiedades o condiciones de contorno, pueden ser descritos mediante al rastreo de la lógica evolutiva de estas totalidades y subtotalidades organizadas. Los fenómenos naturales y sociales se encuentran relacionados (complectere), y entretejidos (complexus) de manera indivisible, por lo cual es inviable un análisis segmentario y atomista de sus partes (Morin, 1990).

Para el nuevo humanismo como propuesta epistemológica, se hace necesaria una metodología que genere recortes arbitrarios de la realidad para su estudio, es decir, sistemas complejos conceptuales, que sirvan para investigar las propiedades emergentes y la composición sistémico del conjunto que, por su interdefinibilidad estructurante ${ }^{11}$, solo pueden abordarse desde la interdisciplina, un nivel de integración epistemológica superior a la simple sumatoria de aportes disciplinares (multidisciplina) y guiada por teorías que trascienden el orden disciplinar mediante una explicación general de los macro-procesos (transdisciplina) ${ }^{12}$. La interdisciplina y los sistemas complejos son dos caras de la misma moneda, y la única forma de atender las urgentes problemáticas que en los albores del siglo XXI amenazan, de las formas más agresivas, la supervivencia del ser humano

11 La interdefinibilidad es un concepto usado por autores de la teoría de la complejidad, entre ellos Humberto Maturana y Francisco Varela (1972). La definición explica la relación que existe entre los elementos de un sistema no descomponible (complejo), en donde el flujo constante de los subsistemas es lo que compone el sistema, superando así los conceptos de interacción e interrelación.

12 Estos tres conceptos nos resultan esenciales en tanto conforman la base de la nueva metodología aquí propuesta, ya que los fenómenos reclaman la interdisciplina debido a la complejidad (indivisibilidad) y la imposibilidad de estudiarlos de manera fragmentada. A su vez, para lograr el marco epistémico propuesto por García (2006), es indispensable acudir a las teorías transdisciplinarias, entre las cuales se puede mencionar al estructuralismo, el materialismo histórico, la teoría general de los sistemas, el PTD del nuevo humanis$m o$, entre otros marcos teórico-conceptuales que trascienden las disciplinas y le dan a los investigadores las bases comunes para la comunicación entre distintos sistemas del conocimiento. 
y su entorno. Solo la humanidad puede salvar a la humanidad por medio de una nueva forma de conocer el mundo.

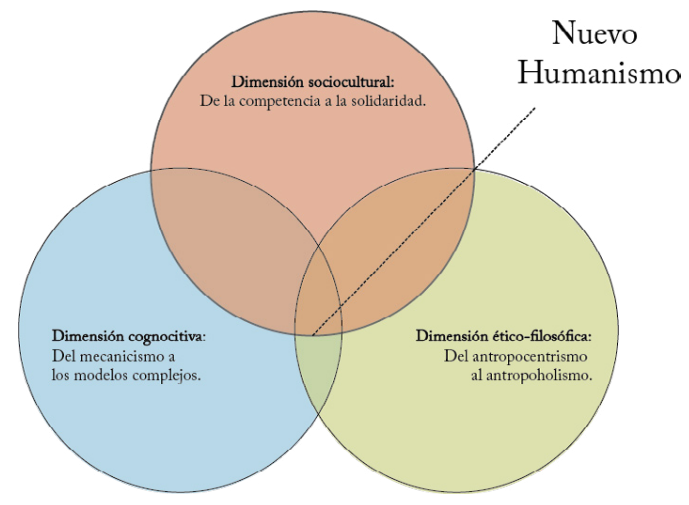

Figura 1: El paradigma tridimensional del nuevo humanismo.

Fuente: Baraona y Mata (2016).

El nuevo humanismo se materializa en el conjunto de procedimientos organizados para la construcción de conocimiento complejo-interdisciplinario y con fundamento ético-filosófico como, a nuestro juicio, tienen otras propuestas pedagógico; pero, sobre todo, se basa de manera estricta en solidos principios epistemológicos que propician un cambio necesario en la forma de hacer ciencia para la autoemancipación de los seres humanos mediante la educación: Ciencia con consciencia para una pedagogía del resistente en el siglo XXI.

\section{III. ¿Por qué una pedagogía nuevo humanista?}

La aspiración de una praxis social nuevo humanista, comprendida como una concepción tripartita de convivencia entre los seres humanos en donde confluyen las dimensiones cognoscitiva, socio-cultural y ético-filosófica, debe surgir desde los momentos iniciales del ser humano y permanecer durante su transitar en la vida. Una educación nuevo humanista requiere, entonces, de una pedagogía consecuente, que atienda el desafío más que teórico, al de la puesta en ejercicio del nuevo humanismo. Una propuesta de pedagogía nuevo humanista debe remitirnos a su comprensión epistemológica de las formas en cómo esta comprensión incide en los elementos que componen una pedagogía coherente, cómo se comunica y se hace realidad en los procesos educativos, pero también, cómo estos procesos educativos la reconstruyen en un continuo. Una epistemología del nuevo humanismo es, en sí misma, una invitación a una nueva forma de conocer, de aprender, de enseñar; para una nueva forma de ser, de convivir. 
Para una pedagogía del nuevo humanismo partimos de reconocer que existe una relación en doble vía entre las sociedades y las construcciones pedagógicas. Así, tanto incide el avance de las sociedades en la evolución de las propuestas pedagógicas, como estas inciden o buscan incidir en la reconfiguración de los procesos sociales como de su organización estructural. Hemos de comprender una pedagogía del nuevo humanismo desde una posición transformadora de la sociedad y no como un factor fundamental para la preservación del poder que la estructura.

La comprensión de los principios generales que caracterizan una pedagogía nuevo humanista se apoya en un breve recorrido por algunos de los enfoques pedagógicos más influyentes. En este recorrido se pretende dar una mirada a sus postulados fundamentales y sus características.

Solano $(2019$, p. 124) reconoce la pedagogía como la reflexión sobre la práctica educativa. Esta reflexión se ha dado desde diferentes perspectivas científicas como la neurobiología, la psicología y la teoría del conocimiento, lo que abre un espectro más amplio de análisis del ejercicio pedagógico. Es de nuestro interés que una pedagogía nuevo humanista extienda las visiones actuales y sea origen de reflexiones y nuevas formas de la práctica educativa en la búsqueda de un tipo de sociedad que comulgue con el nuevo humanismo.

\section{Enfoques pedagógicos modernos}

Solano (2019) resalta, en su ensayo, tres enfoques pedagógicos como dominantes en el siglo XX: El enfoque pedagógico tradicional, el conductismo y el constructivismo, A estos que serán objeto de nuestro análisis se añade el enfoque pedagógico de Paulo Freire y de las ideas de Edgar Morín, el pensamiento complejo y el paradigma nuevo humanista.

\section{El enfoque tradicional}

Con una base fundamental en la escolástica, el enfoque de una pedagogía tradicional está basada en la tradición y en la transmisión de conocimientos de generación en generación. Su perfeccionamiento ha llevado a generar orientaciones pedagógicas (Solano, 2019). Esta configuración de la pedagogía basada en una forma de ver el mundo y de una organización social de naturaleza autoritaria se reflejaba en una pedagogía unidireccional, rígida y sin creatividad (Ocaña, 2017), o en la promoción de esta. Cavazos (2013) resalta la predominancia del método expositivo, de formas de evaluación basadas en la reproducción de los conocimientos adquiridos mediante el método expositivo y repetitivo, cuyo énfasis es 
el resultado. Este enfoque se caracteriza, también, por una relación vertical y autoritaria entre docente y estudiante. El docente como sujeto es concebido como agente transmisor de conocimiento, disociado de la experiencia del estudiante, a quien se define, ante la existencia de alguien que transmite, como el actor que recibe, con poco o ningún espacio para cuestionar, para disentir, para expresar sus interpretaciones y para promover reinterpretaciones.

En términos educativos, posterior al enfoque tradicional el cual es más cercano a un paradigma positivista, la evolución hacia paradigmas como el constructivismo, el paradigma transformativo e, incluso, el pragmático (MacKenzie y Knipe, 2006) dan origen a nuevas formas de comprender el mundo, la construcción del conocimiento y, por supuesto, la educación. Generan teorías de aprendizaje congruentes con dichos paradigmas e incluso consideradas en algunos casos paradigmas educativos. El ingreso y avance de la sicología en el estudio del conocimiento humano conllevó un viraje en las formas pedagógicas tradicionales, al acercar la ciencia al paradigma del conductismo como una forma de comprender la conducta humana.

\section{El conductismo}

Una de las ideas elementales del conductismo se basa en la relación horizontal de la forma estímulo-respuesta como explicación del desarrollo de aprendizajes en el ser humano, a partir de su comportamientos o conductas resultantes como un elemento observable. En esta relación estímulo- respuesta, el comportamiento resultante está completamente determinado por el refuerzo positivo o negativo (Tomic, 1993). De acuerdo con el mismo Tomic (1993), el conductismo considera que el ser humano, tal como los animales, es una "tabula rasa" y su intención es describir, explicar e incidir en el comportamiento.

En términos del proceso educativo, el conductismo como teoría de aprendizaje responde a esta intención de incidir en el comportamiento. Es posible aquí identificar, en términos de la praxis educativa, elementos del enfoque tradicional en relación con la repetición del estímulo como un método clave para reforzar o asumir conductas, las cuales podrían determinar aprendizajes. En cuanto a la evaluación de los aprendizajes, la prueba o examen copan el escenario y son utilizados para demostrar el éxito del aprendizaje. En este sentido, la prueba mide aprendizajes memorísticos obtenidos bien de la lectura o del experto docente. La calificación obtenida como resultado de la prueba es un factor motivante o desmotivante para el estudiante, según si se recibe recompensa o castigo. Este enfoque supone, en ambos, una forma de aprender; en el primero de los casos se 
busca reforzar e incrementar el comportamiento determinado como adecuado y, en el segundo, reducir o eliminar el comportamiento definido como inadecuado.

El desarrollo de la sicología y de la ciencia hacia paradigmas con una mirada más fenomenológica, interpretivista, social e histórica llevó también al desarrollo de paradigmas educativos congruentes, como el constructivismo y socio-constructivismo. Desde la perspectiva de la sicología (Goldsmith y Laks, 2018) se ubica como un punto de inflexión para el éxito de esta misma, el hecho de retomar conceptos relacionados con la mente para explicar los datos observables desde el conductismo. Es quizás aquí en donde el conductismo cede el protagonismo a la revolución cognitiva en sicología (Goldsmith y Laks, 2018), la cual tendrá claramente incidencia en los paradigmas educativos.

\section{El cognitivismo}

Su origen ha sido situado entre los años de 1950 y 1960 y, en relación con los estudios de la mente, fue el paso siguiente después del conductismo. Ese tiempo es posicionado en la historia de la sicología como la revolución cognitiva, la cual abrió el estudio de la sicología hacia la necesidad subyacente de los conceptos mentales esenciales para explicar los datos obtenidos en las observaciones de la conducta, donde dio relevancia a los procesos cognitivos y abrió, a la vez, espacio para el estudio de procesos mentales como la memoria, el desarrollo de nuevo conocimiento y la resolución de problemas, lo cual, sin duda, tendrá un efecto en la educación y en la pedagogía. Las teorías de aprendizaje derivadas de un paradigma de la construcción de aprendizajes con fundamentos en lo cognitivo ponen el énfasis en los procesos de aprendizaje del estudiantado y atienden el cómo se recibe la información, cómo se organiza, se almacena y cómo es recuperada por la mente (Ertmer y Newby 1993). Con el cognitivismo inicia el desarrollo de un rol más activo del estudiantado, pues deja de ser un recipiente receptor de estímulos y emisor de respuestas, para desarrollar actividades como la codificación y transformación de la información. Es posible considerar los avances en el cognitivismo como una puerta de entrada al constructivismo, un fuerte paradigma de aprendizaje que en décadas recientes ha incidido en la educación

\section{El constructivismo}

Bada (2015) reconoce al constructivismo como una de las grandes ideas en educación. Lo consideramos un paradigma, pues atiende la forma diferente de comprender la mente humana y el aprendizaje, al que concibe como construido por 
el ser humano, quien construye sus propios conocimientos y significados sobre el mundo que le rodea, desde su experiencia y desde las reflexiones sobre esa experiencia (Bereiter, 2007). Este principio contrasta con la idea del conocimiento como resultado de la transmisión de información, derivado de un fenómeno del tipo estímulo-respuesta (Von Glasersfeld, 1995). El constructivismo desarrolla aún más la concepción de que el aprendizaje es activo más que pasivo, idea que ya se visualizaba en el paradigma cognoscitivo.

Dos grandes teóricos del constructivismo lo fueron Jean Piaget y Lev Vygotsky. Para Piaget, el niño adquiere conocimientos a través de sus acciones y pasa por etapas, como la asimilación, alojamiento y equilibrio, en el proceso de construcción de conocimiento (Dagar y Yadav, 2016). Vygotsky, por su parte, considera que el proceso de construcción de conocimiento es resultado de la interacción social con otros. Uno de los conceptos teóricos del enfoque vigotskiano que mejor representa el aprendizaje social es la zona de desarrollo próximo (ZDP), entendida como la distancia entre el desarrollo actual y el siguiente nivel de desarrollo potencial determinado por la posibilidad de resolver un problema con la guía de otro. Quizás una de las áreas de los estudios pedagógicos que más se ha visto beneficiada del enfoque es la mediación pedagógica, la cual se ha dispuesto a proveer procesos de construcción de conocimiento como experiencias de aprendizaje, aprendizajes emocionales, diversos modos de representación mediante estrategias de aprendizaje como el andamiaje, estudios de caso, juegos de roles, grupos de discusión y aprendizaje basado en problemas; entre otros (Bada, 2015).

\section{El paradigma humanista en la educación}

Bada (2015) considera como un principio del constructivismo la relación entre las emociones para el aprendizaje. Este principio parece ser un eslabón que, en el desarrollo del estudio de la cognición humana, se acerca al paradigma humanista que privilegia el estudio de las necesidades humanas y sus intereses al reconocer intenciones y valores previos (Huitt, 2009). Para Cavazos (2013), una pedagogía humanista tiene como propósito la formación de la voluntad y del carácter del educando, con una función de preparación para una vida activa, diligente y esforzada.

En el paradigma humanista el estudio de la persona como un todo es un principio cardinal que tiene como objetivos, entre otros, promover la independencia, ser responsable por lo que se aprende, y desarrollar la creatividad, la curiosidad y un interés por las artes (Huitt, 2009). En términos del currículo, el paradigma humanista plantea mayor flexibilidad y da la oportunidad al estudiante de aprender 
lo que quiere y necesita, saber cómo aprender es más importante que el conocimiento disciplinar y la autoevaluación adquiere mayor preponderancia (Berliner y Gage, 1984).

\section{Catorce principios pedagógicos}

Estos principios pedagógicos constituyen, en realidad, una serie de mediaciones cognoscitivas ${ }^{13}$ fundadas en las tres dimensiones en las que se proyecta y, al mismo tiempo, se sustenta el nuevo humanismo. Por cuestiones meramente prácticas y sin que la numeración propuesta a continuación represente algún tipo de orden jerárquico de importancia, daremos un dígito a cada una de las tres dimensiones del PTD: 1. Dimensión socio-cultural (D1); 2. Dimensión ético-filosófica (D2); 3. Dimensión cognoscitiva (D3). A medida que vayamos presentando los principios pedagógicos que dimana del PTD, señalaremos también con cuál o cuáles de las tres dimensiones se relaciona de manera más estrecha. El orden en que aparecen los 14 principios tampoco pone de manifiesto un determinado orden de importancia.

\section{Practicar de forma permanente la empatía circular (D1 y D2)}

En un artículo reciente y aún en vías de ser publicado y al que nos referimos aquí con autorización explícita de su autora Susanne Müller-Usig, 2018), se pone de manifiesto la enorme trascendencia evolutiva e histórica positiva que la empatía ha desempeñado en el desarrollo de la humanidad; $y$, en especial, el significado que para la teoría psicopedagógica y la práctica docente tendría el fenómeno afectivo y cognitivo que constituye la "empatía". A diferencia de la simpatía, que pone el acento en la capacidad para identificarse de manera positiva, pero externa con otra persona o grupo de personas, o con seres no humanos, como pueden ser animales e incluso plantas y entidades físicas carentes de vida propia ("simpatizo con el mundo y todas sus criaturas y creaciones"), la empatía es una capacidad más profunda para sentir "en carne propia" los sufrimientos y alegrías, o todos los estados de ánimo interiores de otro ser humano o grupo de seres humanos y poder, de alguna forma, replicar de manera endógena lo que en principio es un fenómeno humano externo, pero que haya eco en sentimientos, pensamientos y experiencias propias de quien o quienes sienten empatía por otras personas.

13 Ver en otra parte de este artículo la distinción propuesta entre "cognoscitivo" y "cognitivo". 
Y aquí hay que agregar una consideración e imperativo adicional, que nos parece de importancia crucial: la empatía debe ser circular, o mejor dicho, como una suerte de espiral que, en forma constante, asciende a partir de la actitud positiva inicial del docente, hacia formas de interacción grupal cada vez más sinergística.

Este principio dimana de las dos dimensiones del PTD nuevo humanismo: la dimensión 1 (D1) sociocultural y la dimensión 2 (D2) ético-filosófica. En la D1, que enfatiza la solidaridad y el altruismo por encima del egoísmo y el individualismo, la relación es obvia. Y en la D2, tampoco hay mucho que elaborar al respecto: el humanismo es, por definición, una perspectiva ético-filosófica que considera el bien común de la especie como un valor autoevidente y que dispensa de mayor justificación. La empatía circular se funda, en última instancia, en un sentido innato de unidad colectiva, y de intereses universales y comunes aplicados a la convivencia interpersonal y social en general.

\section{Trabajar desde la afectividad (D1 y D3)}

El vínculo entre la afectividad (emociones, sentimientos, afecto, cariño, intimidad en los sentimientos, etc.), los procesos de aprendizaje y la cognición son estrechos, poderosos, e indisolubles (Hilgard, 1980). Por mucho tiempo y en forma predominante, el proceso educativo y el aprendizaje han sido abordados e impulsados por quienes se preocupan por su renovación y transformación constante, en función, casi exclusivamente, del desarrollo de aptitudes y capacidades cognitivas intelectuales fundadas en las habilidades innatas del cerebro humano, y en la ampliación de éstas mediante modalidades de interacción pedagógica apropiadas. Pero ahora, se comienza a vislumbrar, cada vez con mayor claridad, el poder de la vida afectiva sobre el desarrollo tanto del cerebro como del cuerpo en general, de forma que sea, a su vez, provechosa, satisfactoria, saludable y armoniosa. Y no se trata de crear una atmósfera afectuosa entre educandos y educadores, sino también de fomentar la amistad entre educandos, reforzándola de manera incremental mediante la aplicación del primer principio que ya hemos reseñado.

En cuanto a las dimensiones del PTD que nos parecen de especial relevancia para la formulación de este principio pedagógico estaría primero (D1), estrechamente vinculada con (D3), puesto que la trascendencia de una afectuosidad positiva en el proceso de aprendizaje debe ser concebida dentro del contexto sociocultural prevalente en una sociedad determinada (Rogoff, 1990), y esto quizá se consiga solo mediante la experiencia acumulada, y a través del método más simple de todos los que dicta el sentido común: prueba y error. 


\section{Reforzar y elevar la autoestima individual y colectiva (D1 y D3)}

Todo proceso de interacción educativa y de aprendizaje, en un aula o curso determinado, nace desde un punto inicial de trabajo en el que un grupo variado de individuos se reúne o confluye (sobre todo si se trata de educación virtual) en un lugar (ya sea físico o virtual) y en un tiempo acordado de antemano; y esto da comienzo a un ciclo que se desenvuelve en un período cronológico correspondiente a una fase educativa preestablecida. Cada una de esas personas que configuran así un grupo (mejor deberíamos caracterizarlo como un equipo en el marco pedagógico del nuevo humanismo), se incorpora con niveles variados y a veces muy contrastantes de conocimientos y desarrollo intelectual; pero, sobre todo, con sentimiento individuales de valía personal e intelectual dispares (y esto incluye, obviamente, a los docentes involucrados). ${ }^{14}$

Nos parece que este principio se remite en forma muy directa y enfática a las dos dimensiones (D1) y (D3), ya que generar una ambiente que facilite la elevación individual y colectiva de la autoestima es de una importancia sociocultural sobresaliente, no solo por específicas razones pedagógicas que tienen que ver con el proceso de enseñanza/aprendizaje que ya hemos explicado, sino, de manera muy trascendental y general, como forma de contención y resistencia ante las poderosas fuerzas que impulsan una abanico de formas de alienación en nuestra era. Y de forma también casi autoevidente, todo muestra que la relación positiva entre afectividad, autoestima y desarrollo intelectual es intensa, estrecha y constituye, por así decirlo, un círculo virtuoso conducente a un buen desarrollo intelectual.

\section{Aprender aprendiendo a aprender (D1, D2 y D3)}

En una de sus frases más celebradas, Noam Chomsky ha dicho que "el propósito de la educación es mostrar a la gente cómo aprender por sí mismos [sic]. El otro concepto es adoctrinamiento". Esta reflexión pone en evidencia, a nuestro parecer, un principio importante del nuevo humanismo aplicado a la esfera particular de la pedagogía y la práctica docente: que la idea simplista y mecánica de que los educadores podemos "enseñar", entendido este proceso como la transmisión

$14 \mathrm{Y}$ en relación con esto último, la efectividad (entendida en este contexto como: capacidad de lograr el efecto que se desea) real de un cierto ciclo de enseñanza-aprendizaje jamás podrá medirse solo a partir de la transferencia cuantificable de información (que suele ser lo único que miden los exámenes cuantitativos) de docentes a educandos y de aprovechamiento real en términos de conocimiento por parte de estos últimos, sin entrar a considerar el efecto positivo o negativo sobre el sentimiento de autoestima predominante en la mayoría de las personas involucradas en el proceso, en comparación con el momento de arranque de un cierto ciclo lectivo (Fernández, Martínez-Conde y Melipillán, 2009). 
unilateral y unidireccional del conocimiento desde un sujeto "instruido" a otro "ignorante", ha demostrado ser no solo falsa, sino también un obstáculo para el desarrollo integral de los educandos.

Aprender no es solamente un estadio en el proceso general del desarrollo intelectual de las personas; más bien lo debemos concebir como un fenómeno en desenvolvimiento permanente y combinado de habilidades innatas y adquiridas, a lo largo de toda la vida natural de los individuos (Koizumi, 2004). Consideramos, por ello, que se asocia de manera muy profunda con cada una de las tres dimensiones del PTD. Con la (D1), ya que, como hemos discutido previamente en este mismo trabajo, la transmisión de conocimientos en toda organización social humana es de importancia vital, y hacerlo en forma apropiada, ${ }^{15}$ es aún más importante. Con la (D2), dado que si el ser humano aspira a alcanzar su máxima capacidad de autoemancipación, ${ }^{16}$ el cultivo de su inteligencia a través de la educación y la adquisición sistemática de diversos conocimientos, es un factor decisivo. Y con la (D3), pues es evidente que dada la plasticidad inherente y las capacidades innatas del cerebro humano, y considerando todos los avances de la neurobiología y la sicología educativa al campo específico de la enseñanza/ aprendizaje, ello nos sitúa, de lleno, en la esfera de los procesos cognoscitivos a los que alude este dimensión del PTD del nuevo humanismo.

\section{Protagonismo estudiantil (D1, D2 y D3)}

En este fundamento pedagógico planteamos que más que poner en un plano de reciprocidad e igualdad mecánica a educadores y educandos, estos últimos deben ser el verdadero y cada vez más poderoso motor dinámico de la enseñanza, y que el educador debe ser solo un catalizador, un rol modelo, y un sostenedor intelectual del proceso de empoderamiento gradual de los estudiantes. Si los educadores no son capaces de encontrar las formas efectivas de mediación pedagógica como para incitar y despertar un protagonismo estudiantil mayoritario ${ }^{17}$ y prolongado durante un cierto ciclo lectivo, entonces, deberán hacer una drástica y honesta revisión crítica de las circunstancias y factores que han impedido el logro de este gran objetivo.

15 Según términos ya examinados en páginas anteriores.

16 Que hemos analizado en forma más extensa en otras obras, señalando que el giro revolucionario y sin dudas contestatario que significa el surgimiento de discursos filosóficos humanistas en la Grecia Clásica, estaba centrado de manera esencial en situar a nuestra especie como protagonista y forjadora de su propio destino individual y colectivo, mediante el uso de la razón y la voluntad autoemancipadora, sin depender, para ello, o estar supeditada en diversos grados de dependencia, a un orden sobrenatural y divino (Baraona y Mora, 2017).

17 Vale decir, que abarque en forma más o menos sostenida a una mayoría de los estudiantes en el aula o en un curso determinado. 
El protagonismo estudiantil responde, entonces, a dos imperativos fundamentales: 1. De orden pedagógico; 2 . De orden democratizante. Y ambos calzan perfectamente en la (D1) y en la (D3), pero en forma adicional, con un fuerte basamento también en la (D2).

\section{Emancipar la mente para emancipar la vida (D1, D2 y D3)}

El proceso complejo de individuación combina rasgos genéticos heredados, inherentes y peculiares de la especie ${ }^{18}$ y su expresión única en cada persona, con el cúmulo de experiencias e influencias sicoculturales que recibirá y procesará de algún modo a lo largo de su vida ${ }^{19}$. Pero lo que más interesa resaltar, aquí, es que no existe proceso de individuación pleno sin una concomitante socialización; lo cual, en este caso, se traduce en la formación de una consciencia social que convierte a cada persona en un sujeto social determinado, que bien o mal se concibe a sí mismo como forjador de su propio devenir y, por ende, como participante voluntario e involuntario en el conjunto de la vida social.

Así, el rol de los educadores no es adoctrinar, no es entregar soluciones prefabricadas, sino brindar información y estimular el pensamiento autónomo en los educandos. Luego, cada quien, en acorde a su consciencia, debe decidir en forma independiente el camino a seguir. De allí que el optimismo y la esperanza brotan de la voluntad de cambiar el estado de cosas, y no de falsas ilusiones y mentiras convenientes que conducen a la mediocridad y al conformismo.

Este principio pedagógico estaría justificado y anclado en la (D1), puesto que se asocia la emancipación de la mente individual con el proceso general de emancipación sociocultural y viceversa. Y esta dialéctica de la liberación, nos parece, debe situarse de manera complementaria en las dimensiones (D2) y (D3).

\section{De la pedagogía del oprimido a la pedagogía de la resistencia (D2, D1 y D3)}

Aunque el trabajo de Freire fue notable en su momento -y aún lo sigue siendo hasta cierto punto- se trata de una visión algo obsoleta, por dos razones principales: 1 . Desde su época a nuestros días, los movimientos sociales han mostrado que solo la acción proactiva puede alcanzar y sostener justas reivindicaciones emancipadoras. Vale decir, que, en la medida en que los oprimidos disienten y lo manifiestan en luchas reivindicativas urgentes e inescapables, se consigue morigerar,

18 Filogénesis.

19 Epigénesis (Gilbert, 2006). 
e incluso acabar, con una miríada de formas de opresión en nuestras sociedades. ${ }^{20}$ El oprimido deja de serlo desde el momento en que se decide a resistir (no en un sentido reactivo, sino, como hemos dicho, en un sentido proactivo); 2 . La educación formal o institucionalizada desempeña un rol en este proceso, pero no debe exagerarse su importancia. No se puede aprender bien solo en las aulas, sino se aprende de la vida misma, y de esta únicamente podemos aprender-aprehender sus grandes lecciones, si nuestra mente está emancipada (capaz de pensar la vida con una perspectiva crítica y autónoma) o en proceso constante de emanciparse.

Así como la mente humana individual solo puede en última instancia aprender movida por sus propias motivaciones, impulsos y experiencias endógenas, la consciencia personal de cada quien responde, al final de cuentas, a un complejo proceso interior que emerge en relación dialéctica con el entorno cultural, y esto no se puede, en realidad, inducir desde "afuera". Lo que sí puede haber es manipulación de la consciencia individual, mediante el adoctrinamiento y la propaganda, pero no es este fruto espurio del "aprendizaje" al que estamos aludiendo aquí en este trabajo. Este travestismo de un auténtico modelo pedagógico nuevo humanista es un formidable obstáculo que debemos sortear a toda costa, pues de otro modo no haríamos más que reproducir, bajo nuevos ropajes y bajo una nueva retórica demagógica, nuestra función docente y la misión que buscamos llevar a cabo.

Con base en todo lo expuesto hasta aquí, en este punto, con respecto al principio pedagógico 7, terminaremos afirmando que de nuevo vemos una clara y muy poderosa vinculación a la (D2), en segundo lugar y un poco menos intenso, con la (D1) y, obviamente, con la (D3).

\section{Aprender a disentir (D3)}

Los docentes deben concebirse como facilitadores, y así, en tanto catalizadores del proceso de enseñanza/aprendizaje, es fundamental que generen una atmósfera de participación libre y democrática, en el aula, a favor del protagonismo estudiantil. Esto, a su vez, supone promover una ambiente de libre discusión, de debate organizado y respetuoso de las diferencias inevitables, así como de parte del educador hacia el estudiantado, y viceversa. Aprender a debatir es esencial para el desarrollo de las capacidades intelectuales críticas de los educandos; pero, sobre todo, aprender a respetar opiniones opuestas, aunque también es válido

20 Pensamos que una de sus últimas obras, Paulo Freire $(1992,1996)$ comenzaba a formular de manera embrionaria esta propuesta pedagógica. 
todo esfuerzo tendente a desmontar argumentaciones que parezcan falaces, no sustentadas en el uso racional de la lógica, carentes de empatía con el resto de la humanidad (y en especial de sus sectores más vulnerables y sufridos), que anteponen la ideología o algún sistema de creencias a los hechos empíricos objetivos y comprobables, o se expresan, con intolerancia y en forma tajante, sin un uso argumentativo de ideas que admita la posibilidad de contraposición y crítica (Roy, 2018). Por consiguiente, (D3) es de esencial importancia aquí.

\section{Descubrirse a sí mismo, descubriendo el mundo, y viceversa (D3 y D2)}

En acorde con el tercer principio enunciado aquí, el proceso dialéctico de emancipación de la mente/vida únicamente cobra sentido cuando el aprendizaje es un proceso simultáneo de introspección-exospección. Durante largo tiempo, el principio clásico griego de "conócete a ti mismo", ha sido glorificado en Occidente, y ha alcanzado su apoteosis en nuestra era de individualismo-individualista, y de narcisismo vacío y sostenido por bajos niveles de autoestima. En especial, el siglo XX fue una época en la cual buena parte de las artes, las ciencias sociales y naturales, así como la filosofía exaltaban la introspección egoísta, proponiendo buscar las respuestas existencial del ser humano "a encontrar en nuestro interior" las soluciones o respuestas a los enigmas o problemas más angustiantes de la vida, para así hallar una posible senda a la felicidad individual y colectiva.

En referencia a este principio, pensamos que (D3) es de trascendencia mayor y que (D2) está vinculado en forma muy fuerte también a él, pero en un segundo lugar, de todos modos.

\section{De las competencias a las vocaciones y los compromisos (D2 y D1)}

Consideramos pertinente abordar en forma crítica el vocablo "competencias", que ha sido transpuesto de manera, a nuestro juicio, errónea, del ámbito empresarial anglosajón y del inglés al español. A este respecto levantamos dos tipos de objeciones: 1. Crítica semántica: ante todo debemos destacar que la palabra "competencies" (skills) en inglés es mucho más cercana en nuestro idioma a los vocablos "habilidades" o "destrezas", por lo que en realidad es un falso cognado en español en el cual la palabra competencias solía referirse (antes de su errada 
popularización a partir del vocablo inglés) como competiciones de alguna índole; es decir, como "competitions" en inglés, o el acto de competir; ${ }^{21} 2$. Crítica pedagógico-cultural: aunque no haya sido necesariamente con esta intención en todos los casos, ${ }^{22}$ el uso de este vocablo de manera tan facilista y ampliamente difundida en nuestro particular entorno lingüístico-cultural y educativo latinoamericano, y sin el necesario escrutinio crítico previo, parece legitimar, de un modo quizá oblicuo y engañoso, ${ }^{23}$ un mensaje de competencia (“competition") e individualismo.

Entonces, tanto por razones semánticas como semióticas y, por consiguiente, pedagógicas y de honda trascendencia sociocultura, ${ }^{24}$ debemos promover una educación que estimule un desarrollo integral de los individuos y, también, un desarrollo equitativo a nivel social.

Una educación integral para un ser humano integral es aquella que contribuye a formar ciudadanos responsables; vale decir, conscientes de su realidad social, capaces de autoevaluarse con honestidad y que pueden definir una hoja de ruta vital que a grandes rasgos corresponda a su peculiar noción de lo que es para cada quien la realización existencial y el camino la felicidad. Formar ciudadanos conscientes, que luchan por su felicidad personal, por el bien común y por la felicidad colectiva es, por ende, el gran reto de una educación integral y nuevo humanista para el siglo XXI. Y de este modo, ponemos de relieve el contraste entre el modelo pedagógico que estamos proponiendo, y aquel que solo busca incrementar las "competencias" individuales para preparar sujetos funcionales a las demandas del mercado, y así ayudar también a que alcancen ciertas metas económicas, de consumo y materiales en general, que sean consonantes y funcionales a las demandas cambiantes y transitorias del sistema económico. Por el contrario, se trata de contribuir a que los educandos descubran cuáles son sus vocaciones más profundas y aspiraciones más sentidas, para que a partir de ellas puedan forjar una ruta de vida que esté en consonancia con ellas (González Kodela, 2003).

Aquí vemos que en forma descollante, la dimensión (D2) es el punto de partida y, en forma complementaria, por supuesto, estaría la (D1).

\section{Promover la inteligencia holística (D3)}

21 Distinción que no hacemos en español, idioma en el cual solo tenemos el vocablo "competencias" que puede ser utilizado hoy en ambos sentidos ("competencies" y "competitions").

22 Y aunque muchos pedagogos y educadores la utilicen con la mejor intención, el aura ideológica neo-colonial que necesariamente acompaña esta transposición mecánica de una palabra y su sustrato semiótico apenas oculto, a nuestro ámbito cultural y educativo latinoamericano, nos parece retrógrado.

23 Y con tintes "legitimadores" seudopedagógicos.

24 Y política, por cierto. 
El nuevo humanismo propugna, en una de sus tres dimensiones (la científico-cognoscitiva), la búsqueda de una comprensión interdisciplinaria de fenómenos complejos, que desafía y derrotan a los saberes disciplinarios enclaustrados en su particular especialización académico-intelectual. Aquí no se trata de la noción pedagógica de la "inteligencia emocional" o "las inteligencias múltiples" (Pozo, 2006), conceptos que, a pesar de su fuerte sesgo sicologista encierran algo de verdad y de valor, sino más bien del desarrollo, en los educandos, de una capacidad intelectual de naturaleza multidimensional u holística (Montiel y Bravo, 2003), que les permita ver el mundo no como un agregado de parcelas de saberes y fenómenos (Melgarejo y Rodríguez, 2014), sino como un todo orgánico e intercomunicado: como un todo en que múltiples aspectos de la realidad son solo parte de un sistema infinito de vasos comunicantes (Jarvis y Parker, 2005).

Este principio se relaciona sobre todo con la (D3).

\section{Del constructivismo al interaccionismo emancipador (D3)}

A nuestro parecer, una pedagogía nuevo humanista debería alejarse algo de las muy valiosas proposiciones del constructivismo educativo, no para rechazarlas; más bien para superarlas. No se trata solo de "construir saberes y conocimientos"; además, es preciso que ese proceso de construcción nazca de la interacción grupal a menudo espontánea y sin un plan demasiado estructurado, orientada a liberar los talentos innatos de nuestra naturaleza humana, sin necesariamente seguir un orden de "construcción" predeterminado, como quien levanta un edificio, piso por piso.

Nuevamente, a nuestro juicio la (D3) es aquí de muy primordial trascendencia.

\section{Aprender a soñar para poder ser (D3, D2 y D1)}

Siguiendo un largo y continuo hilo conductor esencial del humanismo, desde sus primeras formulaciones explícitas en el siglo $\mathrm{V}$ a.C en la Grecia Clásica, nuestra visión pedagógica nuevo humanista se concentra, sobre todo, en el propósito de contribuir a la formación de personas con un desarrollo integral, que puedan autoemanciparse y, en el proceso, contribuir a la autoemancipación de la humanidad. Y, por ello, concebimos una educación que se propone únicamente despertar y promover el pragmatismo-utilitario entre los estudiantes, como un proceso pedagógico completamente alejado de una formación en consonancia con el nuevo humanismo. No pretendemos negar la importancia de una educación que incluya 
en forma suplementaria una saludable dosis de pragmatismo-utilitario. Pero convertir este enfoque en el central del proceso y las metas de la acción pedagógica no es solo errado, sino incluso catastrófico para el avance de las personas y la sociedad en su conjunto (Leshem, Zion, y Friedman, 2015).

La dimensión de mayor peso en la formulación de este principio pedagógico del PTD es la (D3), apoyada por las otras dos dimensiones (D2) y (D1).

\section{Manos a la práctica (D3)}

Hemos decidido, a propósito, dejar al final el enunciado de este principio, y no por ser el de menor significación, sino precisamente por lo contrario: "aprender haciendo" es premisa crucial e ineludible para "aprender a aprender", que es el segundo fundamento pedagógico abordado en esta secuencia de catorce proposiciones.

Únicamente la práctica directa permite mejorar en cualquier arte, oficio, conocimiento o ciencia, y diremos, por ende, que la relación entre acción y mente, entre cuerpo y cerebro, es tan estrecha, que se trata, apenas, de dicotomías puramente semánticas y conceptuales, pero que, en la realidad misma, todos esos atributos forman una sola e indisoluble unidad. Y siguiendo tal lógica, vemos aquí en acción preponderante a la (D3).

\section{Conclusiones muy preliminares}

Empezaremos por señalar que avizoramos como una tarea ineludible, en un futuro no muy lejano, la preparación de un pequeño manual de técnicas de trabajo en la sala de clases, que permita llevar a la práctica estos principios pedagógicos que constituyen una suerte de primera mediación pedagógica entre el paradigma tridimensional del nuevo humanismo (PTD), y la labor docente que realizamos en el día tras día. Y debe quedar claramente establecido que el PTD es solo un ordenador conceptual que destaca cuáles son las tres grandes dimensiones cognoscitivas y ético-filosóficas que debe abarcar, de algún modo, cualquier propuesta que busque ajustarse a los fundamentos del nuevo humanismo.

Ahora bien, más allá del PTD, tenemos que volver a remitirnos a los dos grandes axiomas del humanismo y del nuevo humanismo; a saber: la idea central ${ }^{25}$ postu-

25 Y muy revolucionaria en el momento en que se plantea por primera vez hace circa 2500 años atrás (Baraona y Mora, 2017). 
lada por el humanismo ${ }^{26}$ en el siglo $\mathrm{V}$ antes de nuestra era, cuando Protágoras y los sofistas propusieron que el ser humano está dotado de la razón y la voluntad necesarias para forjar su propio destino individual y colectivo. En otras palabras, y para retornar a la terminología con la cual hemos estado condensando y expresando esta noción tan revolucionaria en su momento: el ser humano es capaz de autoemanciparse, de avanzar hacia formas de vida y organización social más "humanas", entendidas estas en el sentido corriente de tal vocablo. En esta nueva visión, la humanidad dejaba de estar totalmente sujeta a las fuerzas omnímodas del ámbito sobrenatural y divino, y comenzaba a regirse mediante el libre ejercicio de la razón y la voluntad inherente a su condición mundana y natural. Este giro intelectual, que hoy nos podría parecer trivial, era, no obstante, una idea peligrosa y revolucionaria en una civilización dominada por una cosmogonía fatalista y trágica, en la que la vida humana estaba férreamente supeditada a los caprichos de un panteón divino con poderes sobrenaturales, y a la fuerza suprema e inescrutable del destino.

Reconocer y exaltar el lugar esencial, en la condición humana, de la capacidad inherente (e inalienable agregaría la Ilustración) para romper las diversas cadenas que nos agobian -casi todas de nuestra propia creación- y autoemanciparnos, poco a poco, en diversos sentidos; al tiempo que posiblemente nos encadenamos a nuevas formas de opresión, es, en primera y última instancia, el sello distintivo de todo discurso y toda práctica genuinamente humanista. $\mathrm{Y}$ todos los grandes avances progresistas de la humanidad, no son más que el fruto de nuestro impulso a liberarnos de aquello que nos limita, coarta, humilla, oprime, empobrece y priva de la posibilidad real o ilusoria de poder alcanzar la felicidad de una forma u otra.

Y el nuevo humanismo, es decir, este nuevo brote de praxis humanista que nos proponemos impulsar -sobre todo en el ámbito educativo y de la investigación universitaria- no es otra cosa que situar esos planteamientos esenciales del humanismo, en el contexto histórico y existencial del siglo XXI. ¿Cómo debemos pensar y apoyar la autoemancipación de la humanidad en las condiciones actuales que dominan la existencia individual y colectiva del ser humano?

26 Que aún no se llamaba como tal, pues ese vocablo no aparece sino hasta el siglo XIV en el Renacimiento europeo. Proviene de la voz humanus (humano) y de -ismos que en griego se refiere a una escuela, movimiento, tendencia, doctrina, etc. Y dado que es solo en ese siglo que se utiliza de manera explícita la palabra "humanismo", muchos piensan que es también en esa etapa histórica en que aparecen las nociones fundacionales de la propuesta humanista. No es así, y ese en realidad no es sino el tercer brote de praxis humanista en la historia general del pensamiento humano, precedido por el humanismo greco-romano y por el humanismo de la Edad de Oro islámica, como ya hemos señalado antes en este mismo trabajo (Kristeller, 1982). 
Esa es una pregunta, por supuesto, demasiado amplia, pero es el punto de partida, nos parece, para toda disquisición y práctica humanista en el siglo XXI. Y también es obvio que habría que desglosarla en muchas facetas y aspectos diferentes, y esa es tarea que actualmente estamos abordando en el Centro de Estudios Generales de la Universidad Nacional de Costa Rica, mediante el trabajo de la Cátedra Ibn-Jaldún de Nuevo Humanismo, Hipercomplejidad e Intergnosis, de cuyos alcances y propósitos no es este el lugar adecuado para explayarse sobre ellos.

Si partimos del PTD para esbozar las conclusiones de este ensayo, tenemos que resaltar algo tan simple como fundamental: para que la razón humana y la formación de nuestra consciencia pueda generar una praxis humanista orientada hacia la autoemancipación en una miríada de aspectos de la vida individual y social, es necesario que el razonamiento se origine a partir de aquello lo que suele denominarse como "pensamiento crítico"; ${ }^{27}$ es decir, como la capacidad de nuestra mente para entender las circunstancias subjetivas y objetivas de nuestra vida, sopesarlas en forma crítica, y desear un determinado cambio en algún aspecto de ellas que se considere positivo y necesario. Y una vez que se han establecido las bases conscientes resultantes de este escrutinio, crítico en la medida que indica un deseo o necesidad de cambio ${ }^{28}$, todo dependerá de la volición y de las condiciones favorables o desfavorables ${ }^{29}$ para intentar una determinada transformación. Por ende, la capacidad de la mente humana de sopesar las circunstancias de nuestra vida nos obliga a situarnos en el contexto social más amplio, que es dentro del cual se gesta, necesariamente, todo pensamiento crítico; pues, en última instancia, toda forma de autoemancipación es un proceso de liberación que se efectúa a lo largo del flujo histórico y dentro de contextos socioculturales más amplios.

Pero, lo que más nos concierne ahora, es la poderosa e ineludible relación entre este postulado general sobre la trascendencia del pensamiento crítico, el humanismo, la autoemancipación y el PTD. O en forma aún más específica, la relación entre pensamiento crítico-humanismo-autoemancipación-pedagogía. Los 14 principios pedagógicos que hemos reseñado con anterioridad en este trabajo, intentan, justamente, abarcar, en parte, todas esas mediaciones pedagógicas que

27 Este concepto comienza a aparecer alrededor de mediados del siglo pasado, y desde entonces no ha cesado de cobrar importancia a medida que la ciencia pedagógica se renueva y reinventa en gran medida con visiones más modernas y sofisticadas (Glaser, 1941).

$28 \mathrm{Y}$ por ende descontento con algunas de las circunstancias subjetivas u objetivas, ya sea individuales y/o sociales de nuestra vida, y un deseo e impulso para cambiarlas en forma más favorable a nuestros intereses y necesidades.

29 Lo que a su vez dependerá de la forma como estas sean percibidas en forma bastante subjetiva por una persona o una colectividad (que pueden ser grupos sociales enteros) que se concibe con poderosos intereses comunes. 
van del nuevo humanismo a la docencia, y su práctica cotidiana y concreta en las aulas reales o virtuales.

¿Pero cómo entendemos este concepto de "pensamiento crítico" tan manido y con frecuencia empleado sin ningún esfuerzo de precisión y definición?

En general, de las numerosas, pero poco diversificadas definiciones que se encuentran en referencia a esta noción, casi todas combinan, en diversa medida y con distintos énfasis, tres elementos básicos: el pensamiento crítico es propio de sociedades abiertas que reconocen la importancia de la diversidad de enfoques, puntos de vista e intereses; valoran la importancia de la racionalidad ética ${ }^{30}$ la libre indagación y disquisición, y la libertad de expresión ${ }^{31}$.

Hay cinco aspectos en referencia al "pensamiento crítico" que queremos dejar consignados en forma lo más palpable posible. Pero, además, nosotros consideramos que el pensamiento crítico no puede desarrollarse sin capacidad moral e intelectual de autonomía personal ante modas, opiniones mayoritarias y formas de pensamiento e ideologías hegemónicas, y sin el deseo e impulso motivado por un profundo sentido de justicia. La autonomía, en su visión moral y en su intelecto, es lo que llevó a Galileo a desafiar la poderosa autoridad del Vaticano y a la temible Inquisición, cuando formuló su teoría heliocéntrica. Por consiguiente, no basta simplemente con tener objetividad e integridad intelectual (amor por la verdad), aunque ponga en riesgo incluso nuestra propia integridad física), sino que hay que poseer, además, valor moral e integridad personal. $\mathrm{Y}$ el sentido de justicia, diremos que es un imperativo ético, que tiene que ver con la capacidad para asumir una postura crítica ante las injusticias que se observan (e incluso se experimentan en forma directa y personal) en el entorno social, político y cultural.

30 Algo así como lo que Edgar Morin llamó "ciencia con consciencia".

31 En general, esta noción surge y emerge cada vez con más fuerza a partir de la segunda mitad del siglo XX, con especial presencia en las ciencias de la educación, pero también en otras ciencias sociales y en la filosofía. 


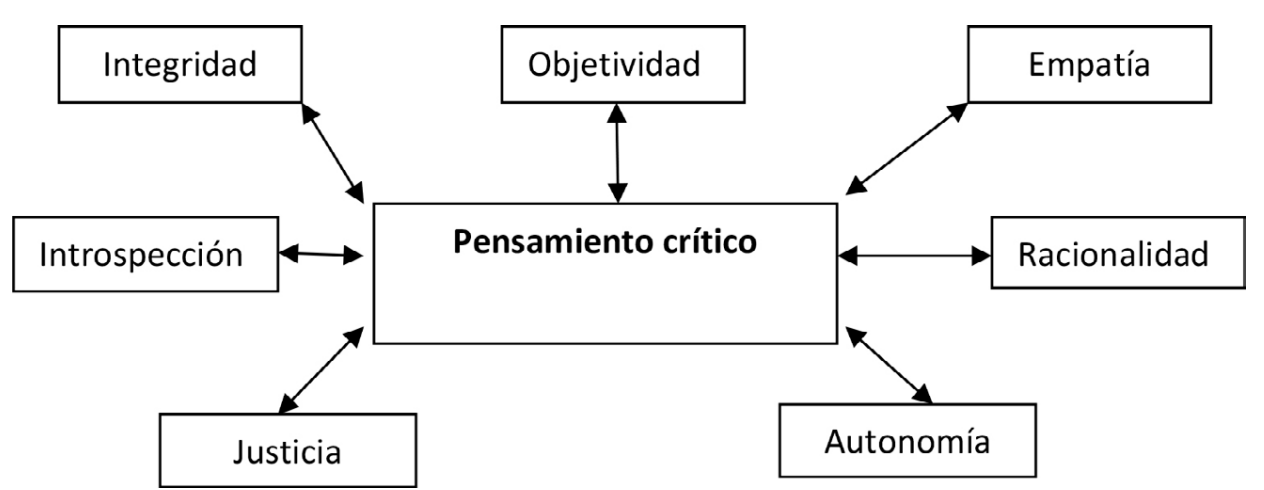

Figura 2: Siete nociones o atributos principales asociados con el pensamiento crítico.

En síntesis, pensar en forma crítica exige un esfuerzo constante por someter a examen objetivo y riguroso cualquier fenómeno, problema, interrogante, dilema, sistema de creencias o conocimientos y suposiciones previas, a la luz de evidencias empíricas e información rigurosa y objetiva que dé sustento a ese abordaje y a escrutinio disidente. Pero ello, supone, a su vez, la habilidad (que se desarrolla con el tiempo y la práctica investigativa) para detectar y definir temas problemáticos que requieran, sugieran o inviten a un escrutinio crítico. Y luego de que este "nudo gordiano" haya sido delineado grosso-modo, se requiere tener la capacidad para escoger las herramientas y los caminos apropiados para indagar sobre ese tema en particular, saber acopiar la información y datos empíricos indispensables, ser capaz de detectar discursos y valores subyacentes ${ }^{32}$ al tópico de interés. También será de esencial importancia poder escoger, entender y utilizar el lenguaje más apropiado; evaluar las evidencias y argumentos; descubrir la existencia (o bien ausencia) de relaciones lógicas entre proposiciones que se han planteado por el sujeto mismo o por otras personas y grupos, y llegar a conclusiones y generalizaciones que pueden ser también puestas a prueba por un pensamiento crítico alternativo.

El pensamiento crítico es, de tal manera, una capacidad que se desarrolla mediante una praxis pedagógica apropiada, y cuya finalidad debe ser central en una amplia gama de materias, aunque posiblemente no en todas. El funcionamiento áulico en el trabajo educativo diario es, sin duda, el factor más decisivo, en última instancia. Podemos estar munidos de las más bellas y elaboradas teorías pedagógicos, pero si en la cotidianeidad del trabajo en el aula de clase no se implementan las técnicas y las mediaciones pedagógicas concretas, particulares y apropiadas,

32 Sobre todo cuando lo que se aborda críticamente es una determinada narrativa de carácter ideológico con la cual en principio se discrepa. 
la labor docente y discente se verá seriamente menoscabada, y la posibilidad de despertar, incentivar y desarrollar el pensamiento crítico entre los educandos fracasará $\mathrm{o}$, al menos, será muy inferior a la deseada. Y la génesis de esta habilidad, pensamos que se ve grandemente posibilitada, si ponemos en práctica, en forma combinada y dialéctica, los 14 principios pedagógicos que son el núcleo principal de este trabajo; principios que se sitúan y se derivan del PTD que es, también, un basamento conceptual-metodológico para construir el nuevo humanismo; constituye este último en turno un quinto brote de praxis humanista situado en el siglo XXI, y continuidad, al mismo tiempo, de un cambio con respecto a esta tradición ético-filosófica.

En un futuro próximo debemos trabajar en configurar un manual práctico de técnicas y mediaciones pedagógicas de empleo diario a nivel áulico (ya sea en el aula física o virtual), y ese sería, a nuestro juicio, el eslabón final de esta cadena de pasos o etapas en la gestación de una pedagogía nuevo humanista, la cual empieza con una comprensión amplia, pero precisa de la génesis del humanismo, el establecimiento de las bases epistemológicas para pensar el nuevo humanismo, y que culmina con sugerencias muy pragmáticas y simples para desarrollar, en el nivel áulico, nuestra labor educativa (vease figura 3). 


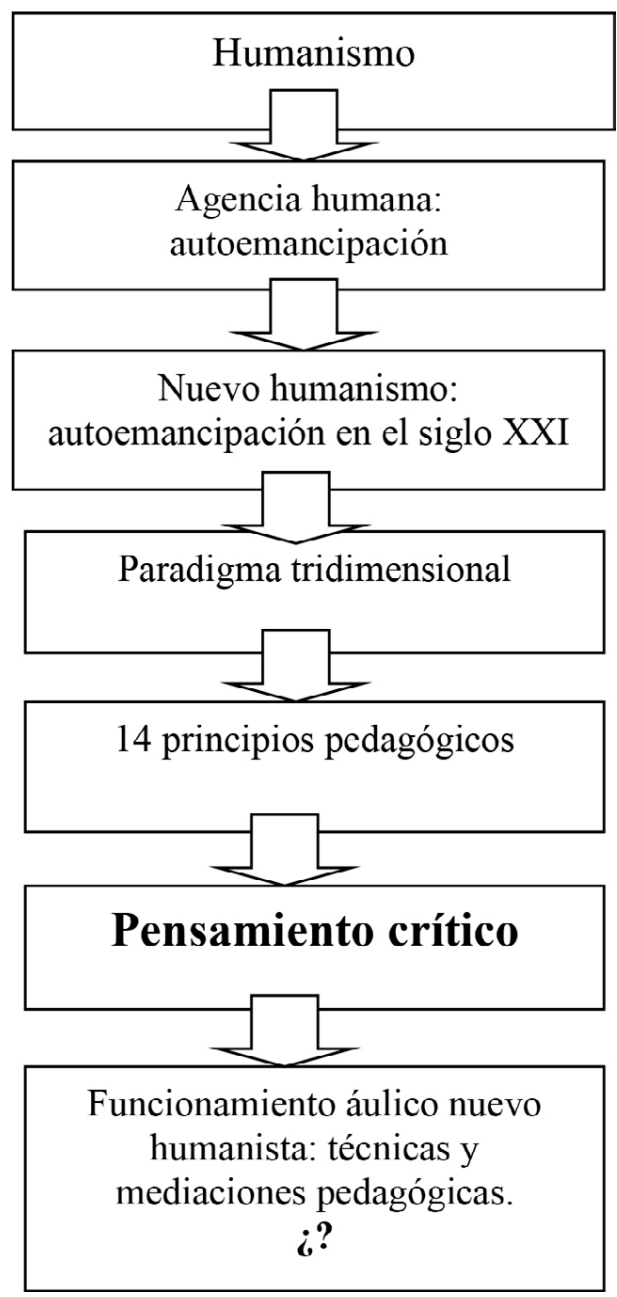

Figura 3: Concatenación de etapas para desarrollar una pedagogía y una práctica docente nuevo humanista. 


\section{Referencias}

Adovasio, J. M., Soffer, O. y Page, J. (2007). The Invisible Sex: Uncovering the True Roles of Women in Prehistory. Routledge.

Árraga de Montiel, M. y Añez de Bravo, A. (2003). Aprendizaje, enfoques epistemológicos y estilos de pensamiento. Encuentro Educacional, 10(1), 23-37.

Bada, Steve O. (2015). Constructivism Learning Theory: A Paradigm for Teaching and Learning. IOSR Journal of Research \& Method in Education I, 5(6), 66-70. doi: https://doi.org/10.9790/7388-05616670

Baraona, M. (2011). Diez ensayos críticos. Editorial Germinal.

Baraona, M. (Enero, 2014). Para un humanismo del siglo XXI: Desafíos y propuestas. Revista de Nuevo Humanismo, 1(1). 11-21.

Baraona, M y Herra, E. (2016). Danzando en la bruma junto al abismo. Las cuatro crisis y el futuro de la humanidad. Arlekin.

Baraona, M. y Mata, E. (2015). Los estudios generales como pedagogía multidisciplinaria en vías a la interdisciplina. Revista de Nuevo Humanismo, 3(1), 39-53.

Baraona, M. y Mora, J. (2017). Hacia una epistemología del Nuevo Humanismo. EUNED.

Berliner, D. C., Gage, N. L. (1984). Educational psychology. Houghton Mifflin Co.

Cavazos, J. R. (2013). Una mirada a la pedagogía tradicional y humanista. Presencia Universitaria, 3(5), 36-45. Recuperado de: http:/eprints.uanl. mx/3681/1/Una_mirada_a_la_pedagogía_tradicional_y_humanista.pdf

Creswell, J. W. (2013). Research Design: Qualitative, Quantitative, and Mixed Methods Approaches. SAGE Publications. Recuperado de: https://books. google.co.cr/books?id=4uB76IC_pOQC

Dagar, V. y Yadav, J. (2016). Constructivism: A Paradigm for Teaching and Learning. Arts and Social Sciences Journal 7: 200. doi: https://doi. org/10.4172/2151-6200.1000200 
Engels, F. (1884/1998). El origen de la familia, la propiedad privada y el Estado. MIA.

Ertmer, P. A. y Newby, T. J. (1993). Behaviorism, Cognitivism, Constructivism: Comparing Critical Features from an Instructional Design Perspective. Performance Improvement Quarterly. doi: https://doi.or$\mathrm{g} / 10.1111 / \mathrm{j} .1937-8327.1993 . t b 00605 . x$

Fernández González, O. M., Martínez-Conde Beluzan, M. y Melipillán Araneda, R. (2009). Estrategias de aprendizaje y autoestima. Su relación con la permanencia y deserción universitaria. Estudios pedagógicos, 35(1), 27-45.

Freire, P. (1967). La educación como práctica de la libertad. Paz e Terra.

Freire, P. (1970). Pedagogía del oprimido. Editorial Tierra Nueva.

Freire, P. (1992). Pedagogía de la esperanza: Un reencuentro con la pedagogía del oprimido. Paz e Terra.

Freire, P. (1996). Pedagogía de la autonomía. Paz e Terra.

García, R. (2000). El conocimiento en construcción. De las formulaciones de Jean Piaget a la teoría de los sistemas complejos. Editorial Gedisa.

García, R. (2006). Sistemas complejos: Conceptos, método y fundamentación. Editorial Gedisa.

Gilbert, S. F. (2006). Developmental Biology. Sinauer Associates, Inc.

Glaser, E. M. (1941). An Experiment in the Development of Critical Thinking. Columbia University Press.

Glasersfeld, E. Von. (1995). A Constructivist Approach to Teaching. In L. P. Steffe \& J. Gale, Constructivism in education. Erlbaum-Hillsdale.

Goldsmith, J. A. y Laks, B. (2018). Battle in the Mind Fields. En Battle in the Mind Fields. doi: https://doi.org/10.7208/chicago/9780226550947.001.0001

González, F. (1984). Hábitos saludables en estudiantes universitarios. Editorial de la Universidad de Valladolid, España.

González, K. M. (2003). Investigación y consolidación de la vocación en el proceso de aprendizaje. Reflexión Académica en Diseño y Comunicación, 4(4), 59-60. 
González Vicén, F. (1984). Sistema. Revista de Ciencias Sociales, 63. 37-58.

Harvey, D. (2005). Breve historia del neoliberalismo. Ediciones Akal.

Hilgard, E. (1980). The Trilogy of Mind: Cognition, Affection and Conation. The Journal of the History of the Behavioral Sciences. April.

Hinchliffe, G. (2001). Education or Pedagogy? Education and Pedagogy, 35(1), $31-46$.

Huitt, W. (2009). Humanism and open education. Educational Psychology Interactive. Valdosta State University. doi: http://www.edpsycinteractive.org/ topics/affect/humed.html

Jarvis, P. y Parker, S. (2005). Human Learning: An Holistic Approach. Taylor and Francis.

Koizumi, H. (2004). The Concept of 'Developing the Brain': A New Natural Science for Learning and Education. Elsevier, 26(7), 434-441.

Knight, Les U. (2015). La espiral del silencio: Densidad demográfica humana. Paidós.

Kristeller, P. O. (1982). El pensamiento renacentista y sus fuentes. FCE.

Kuhn, T. (1971). La estructura de las revoluciones cientificas. FCE.

Leshem, S., Zion, N. y Friedman, A. (2010). A Dream of a School: Student Teacher Envision Their Ideal School. SAGE.

Mackenzie, N. y Knipe, S. (2006). Research Dilemmas: Paradigms, Methods and Methodology. Issues in Educational Research, 16(2), 1-10. doi: https:// doi.org/Retrieved from ERIC.

Maturana, H. y Varela, F. (1972) Mechanism and biological explanation. Philosophy of Science, 39(3), 378-382.

Melgarejo Moreno, I. y Rodríguez Rosell, M. M. (2014). El nuevo entorno educativo de Bolonia: Ágoras transformadas por el esquema tecno-holista. RIUCAM Repositorio Institucional. UCAM.

Mertens, D. M. (2005). Research methods in education and psychology: Integrating diversity with quantitative and qualitative approaches. Research and 
Evaluation in Education and Psychology Integrating Diversity with Quantitative Qualitative and Mixed Methods. Sage Publications.

Morin, E. (1990). Introducción al pensamiento complejo. Editorial Gedisa.

Ortiz, A. (2013). Modelos pedagógicos y teorías del aprendizaje. Ediciones de la U.

Piaget, J. y García, R. (1982). Psicogénesis e historia de la ciencia. Siglo XXI editores.

Pozo, J. I. (2006). Teorías cognitivas del aprendizaje. Edicion Morata.

Rogoff, B. (1990). Apprenticeship in Thinking: Cognitive Development in Social Context. Oxford University Press.

Roy, C. (2018). The Transformative Power of Creative Dissent. In Edmund O'Sullivan, Amish Morrell, Mary Ann O'Connor (Eds.), Expanding the Boundaries of Transformative Learning: Essays on Theory and Praxis. Springer Nature.

Solano, J. (2019). Pedagogía: Itinerario y desafios. Letra Maya.

Spirkin, A. (1983). Dialectical Materialism. Progress Publishers.

Thornton, D. L. (2010). The downside of quantitative easing . Federal Reserve Bank of St. Louis Economic Synopses, 34.

Tomic, W. (1993). Behaviorism and cognitivism in education. Psychology: A Journal of Human Behavior, 30(3-4), 38-46. 
